\title{
Inequity of use of implantable cardioverter defibrillators in England: retrospective analysis
}

\author{
Julie Parkes, Deborah L Chase, Andrew Grace, David Cunningham, Paul J Roderick
}

Health Care Research Unit, University of Southampton, Southampton SO16 6YD

Julie Parkes MRC clinical training fellow Deborah L Chase research fellow Paul J Roderick senior lecturer

Papworth Hospital, Cambridge

Andrew Grace

consultant

cardiologist

NHS Information Authority, Tavistock House, London

David Cunningham technical director, central cardiac audit database

Correspondence to: J Parkes jules@soton.ac.uk

BMJ 2005;330:454-5
Sudden cardiac death occurs in approximately 100000 people annually in the United Kingdom and can be prevented by implantable cardioverter defibrillators (ICDs). ${ }^{1}$ Rates of implantation of ICDs in England have been increasing but lag behind those in other western European countries and North America. The National Institute for Clinical Excellence has recommended indications for use in patients with ventricular arrhythmias and proposed an annual implantation rate of 50 per million population. ${ }^{2}$ We present data on current use, geographical and social equity, and barriers to care in the provision of ICDs in England.

\section{Methods and results}

We used the national pacemaker and ICD database of implantations done in 1998-2002 to derive national rates. We used a dataset from 1998 to 2000, in which improvements in the quality and completeness of data had been made, to derive rates of implantation of new ICDs by English health region. We calculated indirect age and sex standardised ratios of ICD use by health region by using regional population data divided into five year age bands ( 0 to $85+$ years). We assessed equity by using proxy measures for need for ICDs-namely, regional standardised mortality ratios for ischaemic heart disease-and population fifths of deprivation determined using the Townsend index at census ward level and 1991 census data. We did a national postal questionnaire survey of all recorded ICD centres in England to establish perceived barriers to implantation.

The crude rate of implantation of new ICDs in England rose from 12.4 (95\% confidence interval 11.5 to 13.5$)$ per million in 1998 to 30 (28.7 to 31.7 ) per

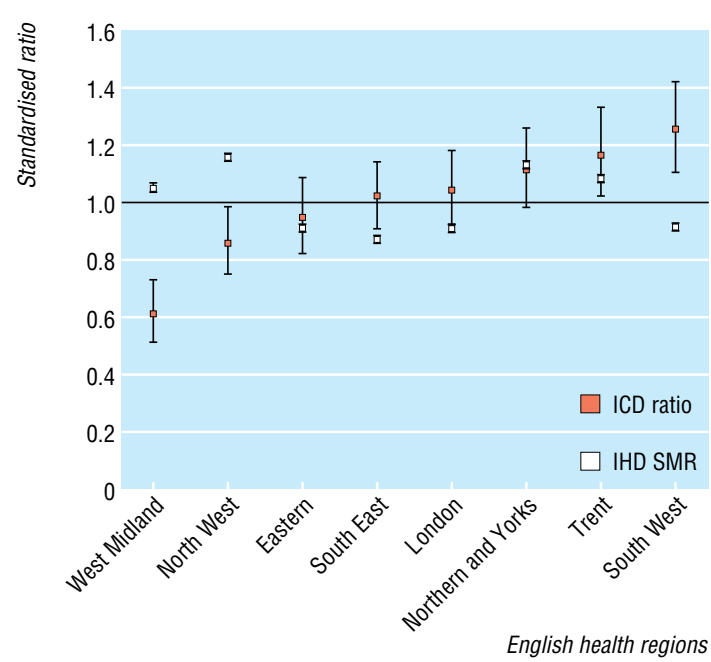

Age and sex standardised ratios of implantable cardioverter defibrillator (ICD) use and standardised mortality ratios for ischaemic heart disease (IHD SMR) in English health regions, 1998-2000 million in 2002. Regional standardised ratios of use ranged from 0.6 to 1.25 (figure). Significant regional differences in standardised rates of implantation existed ( $\chi^{2}$ for heterogeneity, $\mathrm{P}=0.005$ ), although we found no consistent geographical pattern. Differences between implantation and need in five out of eight regions $(95 \%$ confidence intervals for standardised ICD implantation and standardised mortality ratio for ischaemic heart disease did not overlap) suggested inequity. A significant inverse relation existed between standardised ICD implantation and fifths of deprivation $(\mathrm{P}=0.005$, test for trend using a Poisson regression model), ranging from 1.09 to 0.85 (least to most deprived), indicating that an inverse care law may be operating.

The survey response rate was $74 \%(26 / 35)$. The three most commonly perceived barriers to care for patients eligible for an ICD were identification of patients and referral to implanting centres, staff capacity, and funding for treatment. All of the respondents recorded that they expect to see a large increase in demand for ICDs in the future.

\section{Comment}

Use of ICDs varies between English health regions, and use is not commensurate with need. Although incomplete data could be contributing, an inverse care law seems to be operating. This, along with the slow diffusion of the technology and setting of services predominantly in larger tertiary centres, is similar to the pattern previously seen for coronary revascularisation. ${ }^{34}$

Demand for ICDs will probably increase in the future, particularly in view of expanding indications with randomised evidence of the benefits of ICDs in post-myocardial infarction patients with a low left ventricular ejection fraction. ${ }^{5}$ Planned expansion of implanting centres and resources are needed to tackle low levels of referral, geographical and social inequity, and the expected increase in demand for ICDs. Strategies should include referral guidelines and targeted education to ensure appropriate identification and referral of eligible patients. These analyses highlight the value of robust national data to inform service development and the need for adequate resources to collect and analyse such information.

We thank Scot Harris for statistical support and Mora Cunningham, administrator of the national pacemaker and ICD database.

Contributors: JP led the project, cleaned the dataset, did the analyses, constructed the questionnaire and conducted the survey, wrote the first draft of the paper, and is the guarantor. DLC did the analyses, conducted the survey, and helped in writing the paper. AG helped with the survey, commented on drafts, and provided clinical perspective and support to the study. DC is project leader of the national pacemaker and ICD database,

This article was posted on bmi.com on 4 February 2005: http://bmi.com/ cgi/doi/10.1136/bmj.38337.635648.82 


\section{What is already known on this topic}

Implantation of implantable cardioverter defibrillators in England lags behind most western European and North American countries

\section{What this study adds}

An inverse care law seems to be operating on implantation of new implantable cardioverter defibrillators in England

Demand for implantable cardioverter defibrillators is likely to increase in the near future, and a pressing need exists to tackle any inequity and perceived barriers to care

provided the 1998-2000 dataset in which data quality and completeness had been improved, and commented on drafts of the paper. PJR oversaw the project, supervised JP and DLC, supplied epidemiology expertise for analyses, and commented on drafts of the paper.
Funding: AG and JP are orant holders of HTA grant 93/23/04 (a review of the evidence on the effects and costs of implantable cardioverter defibrillator (ICD) therapy in different patient groups, and modelling of cost effectiveness and cost utility for these groups in a UK context). Professor Martin Buxton is the principal investigator of this study. DLC is funded by an NHS South East Research and Development Fellowship.

Competing interests: None declared.

Ethical approval: Not needed for this study, as it used aggregated anonymised data and no patient contact.

Ezekowitz JA, Armstrong PW, McALister FA. Implantable cardioverter defibrillators in primary and secondary prevention: a systematic review defibrillators in primary and secondary prevention: a systematic revic

2 National Institute for Clinical Excellence. Guidance on the use of implantable cardioverter defibrillators for arrhythmias. London: NICE, 2000. (Technology Appraisal Guidance No 11.)

3 Payne N, Saul C. Variations in use of cardiology services in a health authority: comparison of coronary artery revascularisation rates with prevalence of angina and coronary mortality. BMJ 1997;314:257-61.

4 Langham S, Basnett I, McCarthy P, Charles Normand C, Pickering J, Sheers D, et al. Addressing the inverse care law in cardiac services. J Public Health 2003:25:202-7.

5 Moss AJ, Zareba W, Hall WJ, Klein H, Wilber DJ, Cannom DS, et al. Prophylactic implantation of a defibrillator in patients with myocardial infarction and reduced ejection fraction. N Engl J Med 2002;346:877-83. (Accepted 14 December 2004)

doi $10.1136 /$ bmj.38337.635648.82

\title{
DRUG POINTS
}

\section{Nausea and vomiting due to insulin glargine in patient with type 1 diabetes mellitus}

\author{
Anthony N Dixon, Stephen C Bain
}

Insulin glargine is a new insulin analogue with delayed absorption and a prolonged duration of action. ${ }^{1}$ A 34 year old woman who had had type 1 diabetes for six years had previously been treated with premixed biphasic isophane insulin (Humulin M3), twice a day. This regimen had been changed to a basal bolus regimen of Actrapid and Insulatard during pregnancy, but she subsequently resumed twice daily injections (but this time with Mixtard 30). She reported no side effects on any of these preparations. She had no other serious illness and no complications of diabetes.

After a period of suboptimal glycaemic control, she was changed to a basal bolus regimen of Actrapid and insulin glargine. Within 24 hours she complained of nausea. Pregnancy and infection were excluded, but she remained nauseous for six weeks. During this time her glycaemic control improved (her $\mathrm{HbA}_{1 c}$ concentration decreased from $9.8 \%$ to $8.6 \%$ ), but the nausea began to lead to frequent vomiting, which could not be controlled with antiemetics. Insulin glargine was replaced with Insulatard, and her symptoms settled over two days.

Over the next three months she remained well, but her glycaemic control deteriorated and she requested that she try insulin glargine again. Nausea returned within a few hours and continued for several days until insulin glargine was again withdrawn

Glargine is usually well tolerated, with side effects limited to irritation at the injection site. ${ }^{2}$ The Committee on Safety of Medicines (via its "yellow card" reporting scheme) has received three other reports of nausea and two of vomiting since the product was launched in the United Kingdom (see www.yellowcard.gov.uk). These side effects are clearly important in type 1 diabetes since they may predispose to diabetic ketoacidosis. Moreover, prolonged periods of nausea may be erroneously attributed to gastric autonomic neuropathy, leading to unnecessary investigation and treatment.

Contributors: AND wrote the article and SCB treated the patient and edited the text.

Funding: None.

Competing interests: SCB has received funding from Aventis and other insulin manufacturers for attending symposiums, organising educational sessions, and supporting employment of staff.

1 Heinemann L, Linkeschova R, Rava K, Hompesch B, Sedlak M, Heise T. Time-action profile of the long-acting insulin analogue glargine (HOE901) in comparison with those of NPH insulin and placebo. Diabetes Care 2000;23:644-9.

2 Campbell RK, White JR, Levien T, Baker D. Insulin glargine. Clin Ther 2001;23:1938-57.

\section{Endpiece}

\section{God, surgeon, medicine, patient}

Hippocrates in his Aphorisms, as Galen writeth sure, Saieth, foure things are needfull to every kind of cure, The first, saith he, to God belongeth the chiefest part, The second to the Surgeon, who doth apply the art, The third unto the medicine, that is dame Natures friend

The fourth unto the patient, with whom I heere will end.

Clowes W. A profitable and necessarie booke of observations. London: 1596

Jeremy Hugh Baron,

honorary professorial lecturer

Mount Sinai School of Medicine, New York 